\title{
A rare case of congenital bilateral membranous choanal atresia with oesophageal atresia in a neonate
}

\author{
Rabindran $^{1}$, Parakh $\mathbf{H}^{2}$ \\ ${ }^{1}$ Dr.Rabindran, Consultant Neonatologist, Sunrise Superspeciality Children's Hospital, Hyderabad, ${ }^{2}$ Dr.Hemant Parakh, \\ Consultant Neonatologist, Sunrise Superspeciality Children's Hospital, Hyderabad, India
}

Address for Correspondence: Dr Rabindran, E mail: rabindranindia @ yahoo.co.in

\begin{abstract}
Congenital Choanal Atresia is the developmental failure of the posterior choanae to communicate with the nasopharynx . Bilateral choanal atresia is an otolaryngology emergency as neonates are obligate nose breathers. Associated malformations are common.We report a case of Congenital Bilateral Membranous Choanal Atresia whose evaluation revealed associated esophageal atresia. Awareness of such associated anomalies is a must for prompt management of such babies.
\end{abstract}

Key words: Choanal Atresia, Oesophageal Atresia, Membranous Choanal Atresia

\section{Introduction}

Congenital Choanal Atresia is the developmental failure of the posterior choanae to communicate with the nasopharynx. It is extremely rare with a calculated incidence of 3 to 9 per 100,000 live-births [1,2]. Bilateral choanal atresia is an otolaryngology emergency because the affected infant is an obligate nose breather. Associated malformations occur in $47 \%$ of cases [3]. Surgical correction through transpalatal, transnasal, transseptal, sublabial \& transnasal endoscopic approaches have been used. Oesophageal atresia occurs in 1/3000 - 4500 live births [4]. It presents with excessive frothy, oral secretions with choking, cyanosis, coughing at attempted feeding. A plain X-ray shows the tip of catheter arrested in the superior mediastinum (T 2-4). About 30-70\% babies with Oesophageal atresia have associated anomalies $[4,5,6]$. The operative management is either one stage or staged operation depending on the gap, prematurity \& associated anomalies.

\section{Case Report}

A preterm 32 week baby boy weighing $2 \mathrm{~kg}$ was born to a 28 year old primi mother by vaginal delivery. Baby had delayed cry after birth. Apgar was 2 at 1', 5 at 10'\& 7 at 20'. Baby was resuscitated with bag and mask resuscitation. On routine examination at birth there was failure to pass Nasogastric tube bilaterally. Bilateral choanal atresia was suspected \& Airway was secured with oral airway. Baby was in respiratory distress in the form of tachypnea, retractions and was maintaining saturations with hood box oxygen with oral airway insitu.

Baby was admitted \& started on Oxygen, iv fluids \& iv antibiotics. Orogastric tube number 8 was passed which stopped at $11 \mathrm{~cm}$. CXR was done which was suggestive of Oesophageal Atresia.

Opthalmologist opinion was taken which was suggestive of plenty of peripheral retinal hemorrhages in right eye with no coloboma in the retina. 2D ECHO was suggestive of small midmuscular Ventricular septal defect \& moderate Patent ductus arteriosus with Left to Right shunt \& mild to moderate PAH. X-RAY Gastrograffin swallow was done, which showed focal dilated esophagus with contrast stasis noted upto D3 level. Lower esophagus was not demonstrable

The neonate must be kept nil by mouth, commenced on intravenous fluids and nursed supine in a head up position (approximately 30 to 60 degrees). After stabilization the baby was referred to surgical centre for further management. 


\section{Case Report}

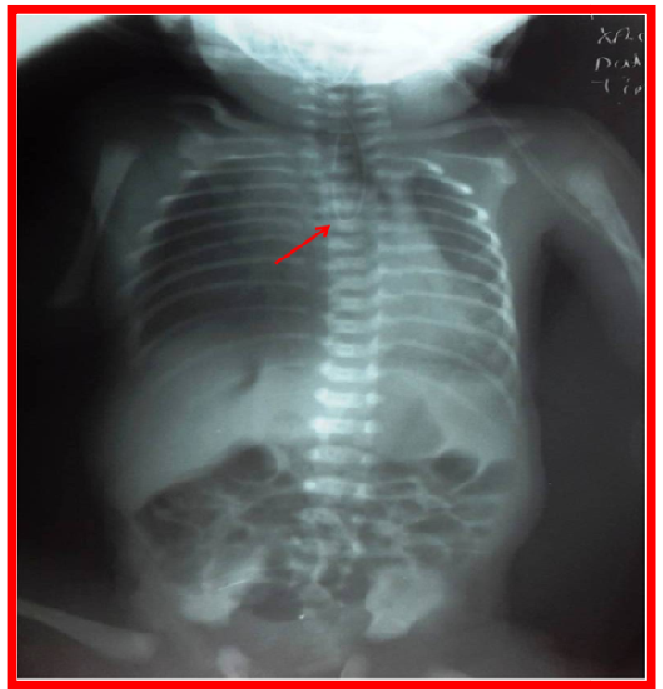

Figure 1: CXR showing coiling of orogastric tube which is blocked from entering the distal esophagus by the esophageal atresia

CT scan Paranasal Sinus, Neck \& Chest-Plain with Virtual Bronchoscopy was done which showed soft tissue dense membrane in the posterior choanae.
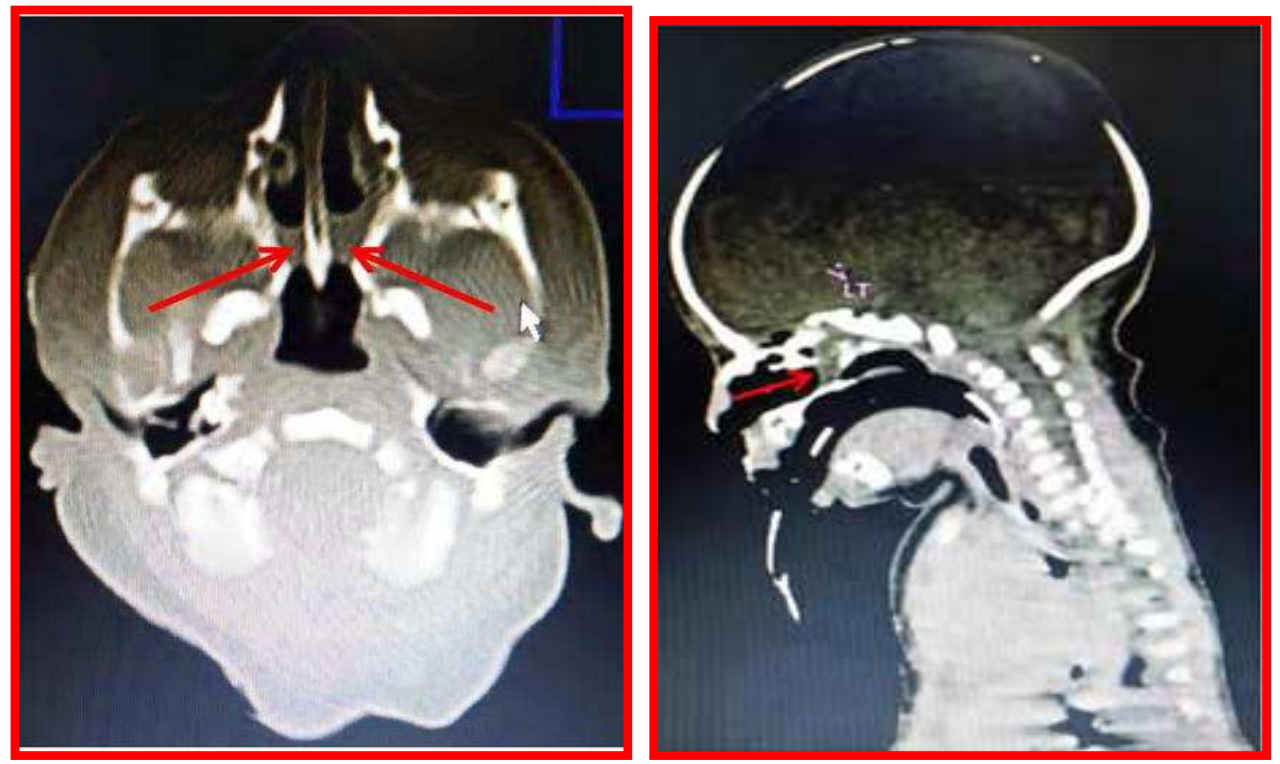

Figure 2: CT Axial and Sagittal Reconstruction Showing Thin Membrane in The Posterior Choanae

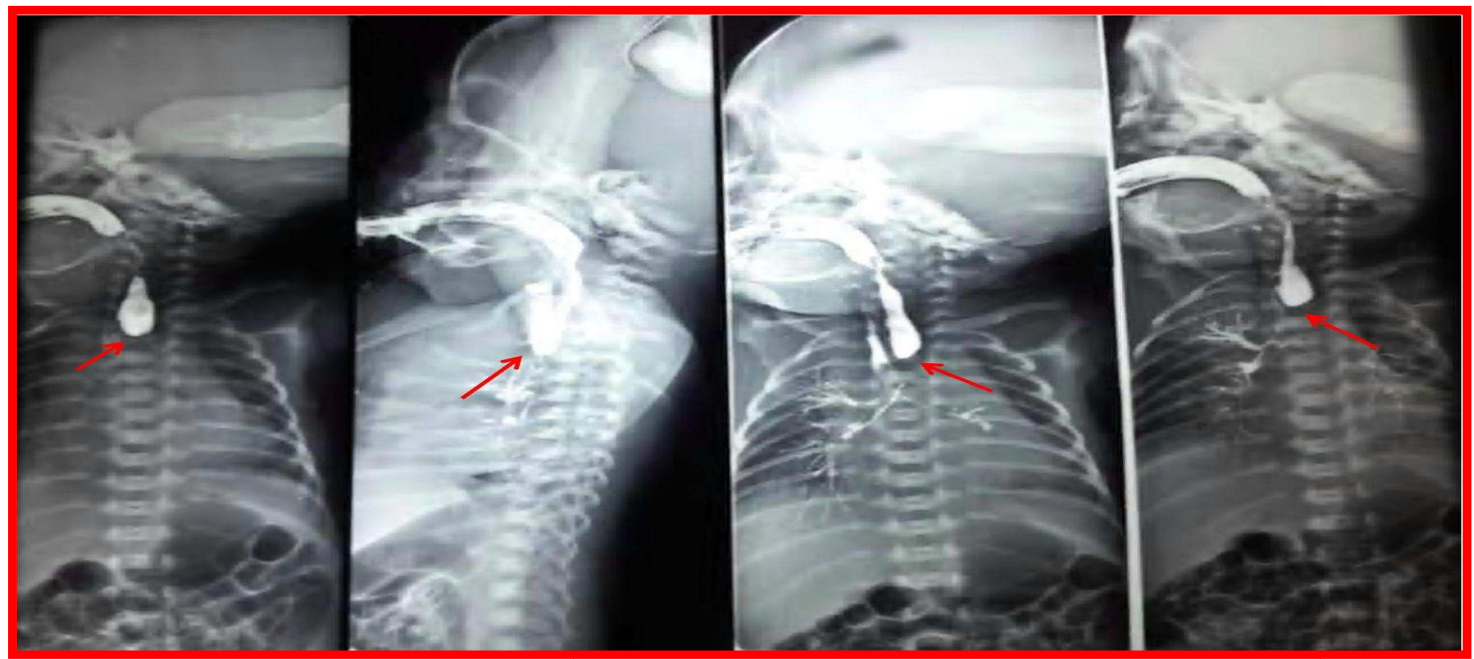

Figure 3: X-Ray Gastrograffin swallow showing Esophageal atresia 


\section{Case Report}

\section{Discussion}

Congenital Choanal Atresia is the developmental failure of the posterior choanae to communicate with the nasopharynx [7]. Proposed theories are Persistence of buccopharyngeal membrane, Failure of bucconasal membrane of Hochstetter to rupture, Medial outgrowth of vertical and horizontal processes of palatine bone, Abnormal mesodermal adhesions in choanal area \& Misdirection of mesodermal flow. Bilateral choanal atresia is an otolaryngology emergency because the affected infant is an obligate nose breather [5]. A small feeding tube could be used to determine the choanal patency. Rhinogram shows blockage of radiopaque dye at the posterior choanae. Flexible fiberoptic endoscope assesses the deformity. The automatic tympanometer can be used to screen newborns for congenital choanal atresia. Associated malformative syndromes are CHARGE (coloboma, congenital heart disease, choanal atresia, mental and growth retardation, genital anomalies, ear malformations and hearing loss), DiGeorge, Apert, and Antley Bixler syndromes [8]. Unilateral atresia occurs more frequently on right side. Our case is a membranous choanal atresia a rare variety of choanal atresia. Surgical correction through transpalatal, transnasal, transseptal, sublabial \& transnasal endoscopic approaches have been utilized $[9,10]$. The surgical approach is determined by the thickness of bony atresia plate [11]. A major long term complication is recurrent ear infections leading to conductive hearing loss.

Oesophageal atresia presents with excessive frothy, oral secretions with choking, cyanosis, coughing at attempted feeding [12]. Nasogastric tube typically stops at $10-12 \mathrm{~cm}$ from the lower alveolar ridge; the normal distance to gastric cardia being approximately $17 \mathrm{~cm}$. A plain X-ray shows the tip of catheter arrested in the superior mediastinum (T 2-4). Three-dimensional CT scan coupled with reformation in three orthogonal planes may have a complementary diagnostic role [13,14]. Preoperative care concentrates on avoiding aspiration pneumonia and includes elevating the head to avoid reflux and aspiration of the stomach contents, using a suction catheter to continuously remove mucus and saliva that could be inhaled, placement of a gastrostomy tube if necessary \& with holding feeding by mouth. The operative management is either one stage or staged operation depending on the gap, prematurity \& associated anomalies[15]. Early complications include anastamotic leak \& oesophageal stricture. Delayed complications include gastrointestinal reflux, disordered peristalsis, and tracheomalacia. The worst prognosis is in those patients with associated cardiac, chromosomal, or major pulmonary anomalies. Birth weight is also a prognostic indicator. Waterston classification of risk groups [16], distinguished between three groups of babies: infants $>2500 \mathrm{~g}$ with no abnormalities (Group A), those 2000$2500 \mathrm{~g}$ with no other abnormalities or $>2500 \mathrm{~g}$ with moderate associated abnormalities (Group B), infants with birth weight $<2000 \mathrm{~g}$ with no other abnormalities or higher birth weight with severe cardiac anomalies (Group C). Spitz classification has now identified a birth weight of $<1500 \mathrm{~g}$ and major congenital heart disease as being the worst prognostic group with a survival rate of $22 \%$ compared with a survival rate of $97-100 \%$ in those babies $>1500 \mathrm{~g}$ without major heart disease [17].

\section{Conclusion}

Awareness regarding the examination of nasal patency \& complete evaluation of associated anomalies as esophageal atresia in our case helps in prompt management of such babies. A multidisciplinary approach is essential to enable the best outcome in these patients.

\section{References}

1. Case AP, Mitchell LE. Prevalence and patterns of choanal atresia and choanal stenosis among pregnancies in Texas, 1999-2004. Am J Med Genet A. 2011 Apr;155A(4):786-91. doi: 10.1002/ajmg.a.33882.Epub 2011 Mar 17

2. V. Raveenthiran. Carbimazole Embryopathy and Choanal Atresia. Journal of Neonatal Surgery 2014;3(1):5.

3. Khaled Al-Noury and Alsaid Lotfy . Role of Multislice Computed Tomography and Local Contrast in the Diagnosis and Characterization of Choanal Atresia. International Journal of Pediatrics. Volume 2011 (2011), Article ID 280763, 6 pages; http://dx.doi.org/10.1155/2011/280763

4. Muraji T, Mahour GH. Surgical problems in patients with Vater associated anomalies. J Pediatr Surg. 1984 Oct;19(5):550-4.

5. Holder TM ${ }^{1}$, Ashcraft KW, Sharp RJ, Amoury RA. Care of infants with esophageal atresia, oesophageal fistula, and associated anomalies. J Thorac Cardiovasc Surg. 1987 Dec;94(6):828-35.

6. Ein $\mathrm{SH}^{1}$, Shandling B, Wesson D, Filler RM.

Esophageal atresia with distal tracheooesophageal fistula: Associated anomalies and prognosis in the 1980s. J Pediatr Surg. 1989 Oct;24(10):1055-9.

7. Cheung $\mathrm{R}^{1}$, Prince M. Comparison of craniofacial skeletal characteristics of infants with bilateral choanal atresia and an age-matched normative population: computed tomography analysis J Otolaryngol. 2001 Jun;30(3):173-8.

Available online at: www.ijmrr.in

446 | P a g e 


\section{Case Report}

8. Der Kaloustian VM, Tewfik TL. Congenital Anomalies of the Ear, Nose and Throat. Oxford, United Kingdom: Oxford University; Press; 1997

9. Ramsden JD ${ }^{1}$, Campisi P, Forte V. Choanal atresia and choanal stenosis. Otolaryngol Clin North Am. 2009 Apr;42(2):339-52, x. doi: 10.1016/j.otc.2009.01.001.

10. Friedman $\mathrm{NR}^{1}$, Mitchell RB, Bailey CM, Albert DM, Leighton SE. Management and outcome of choanal atresia correction. Int J Pediatr Otorhinolaryngol. 2000 Jan 30;52(1):45-51.

11. Deutsch E, Kaufman M, Eilon A. Transnasal endoscopic management of choanal atresia Int J Pediatr Otorhinolaryngol. 1997 May 4;40(1):19-26.

12. Spitz L. Oesophageal atresia. Orphanet J Rare Dis. 2007 May 11;2:24. doi:10.1186/1750-1172-2-24. doi:10.1186/1750-1172-2-24.
13. P.Ou, E.Seror, W.Layouss, Y.Revillon, and F.Brunolle. Definitive diagnosis and surgical planning of H-type tracheoesophageal fistula in critically ill neonate: First experience using air distension of the esophagus during high resolution computed tomography acquisition. J. Thorac. CardioVasc.Surg., April 1, 2007;133(4):11161117.

14. McHugh K. CT Dose Reduction in pediatric patient. AJR Am J Roentgenol. 2005 May;184(5):1706; author reply $1706-7$.

15. Grosfeld JL, Ballantine TV. Esophageal atresia and tracheo-esophageal fistula ,effect of delayed thoracotomy on survival. Surgery. 1978 Sep;84(3):394-402.

16. Waterston DJ, Bonham-Carter RE, Aberdeen E. Oesophageal atresia: Tracheo-oesophageal fistula. A study of survival in 218 infants. Lancet. $1962 \mathrm{Apr}$ 21;1(7234):819-22.

17. Spitz L. Oesophageal atresia: Past, present, and future. J Pediatr Surg. 1996 Jan;31(1):19-25.

\section{How to cite this article?}

Rabindran, Parakh H. A rare case of congenital bilateral membranous choanal atresia with oesophageal atresia in a neonate. Int J Med Res Rev 2015;3(4):444-447. doi: 10.17511/ijmrr.2015.i4.078. 